International Business Management 6(6): 665-675, 2012

ISSN: $1993-5250$

(C) Medwell Journals, 2012

\title{
Job Satisfaction Framework: The Role of Market Orientation, Service Orientation and IT Infrastructure
}

\author{
Hamed Gheysari, Amran Rasli and Parastoo Roghanian \\ Faculty of Management and HRD, University Technology Malaysia (UTM), \\ 81310 Skudai, Johor, Malaysia
}

\begin{abstract}
The study proposes to investigate whether Market Orientation (MO), Service Orientation (SO) and Information Technology Infrastructure Capability (ITIC) affect the Job Satisfaction (JS) as well as to identify factors and barriers that influence the implementation of $\mathrm{MO}, \mathrm{SO}$ and ITI capability to improve JS in banking industry. About 20 participants from 4 departments from Mellat Bank of Iran have been involved in the qualitative research process which was blended with the case study design. Significant patterns and themes are identified and presented in this study. A conceptual research framework based on the qualitative analysis on how MO, SO and ITI capability improve JS is proposed. The model comprises of five major components: market orientation, service orientation, job satisfaction, IT infrastructure capability and factors and barriers that influence the implementation of $\mathrm{MO}$, SO and ITI capability to improve JS. Extensive empirical analyses in the real world environment in other industries would be helpful to verify and generalize this approach. This study provides guidelines for bank industry to implement effective market orientation and service orientation initiatives and information technology infrastructure to improve job satisfaction.
\end{abstract}

Key words: Job satisfaction, market orientation, service orientation, IT infrastructure, banking industry

\section{INTRODUCTION}

Internationalization has largely lead the banking industry undergoes very fast transformations as well as partaking in a more competitive environment. Moreover, due to global deregulation, numerous new banks are being established which brings about clients with higher demands. This is why bank management has adapted marketing strategies by changing from passive conservatism to active business orientation. With these changes and increasing competition, it is now a matter of survival for banks.

The 1960 s and 1970 s witnessed a change in business competitive management approaches from doing the job right to doing the right job. The buzzwords optimization and cost reduction also changed to customer satisfaction and employee contentment and loyalty (Rogers et al., 1994). When a company is able to provide exceptional value to its clients by finding and catering to their specific desires better than competitors, then it attains competitive advantage. Once achieved, competitive advantage should be maintained by allocating time to train, motivate and support company's employees. In addition, both market and service orientation need to be investigate the function of managers, employees and company policy and procedure efficiency.
Crosby and Stephens (1987) argue that the main factor in satisfaction with the service received is actually the customers contact with the service providers which is relevant to banking where customers come across and necessitate lots of personal touch. Therefore, keeping employees most content and motivated is vital for banks and similar businesses with high customer interaction levels in order to achieve profit and goals. This is how, now-a-days, banks are faced with the challenge of maintaining competitive advantage. A possible solution to this challenge is marketing concept encompassing both market and service orientation. Marketing accentuates putting priority on customer interests and considering their needs in order to create strong, long-term customer relations. If customer needs are well understood then customer satisfaction is higher and long-term company profitability improves, respectively. Thus, marketing concept is vital to gaining competitive advantage.

Moreover, employee market orientation is also particularly important in the service industry and is a potential solution for banks to maintain competitive advantage and establish a winning position in today's fiercely competitive business atmosphere. Therefore, treating bank employees like valued internal customers and facilitating a market-oriented culture among them can lead to a bank achieving and maintaining competitive

Corresponding Author: Hamed Gheysari, Faculty of Management and HRD, University Technology Malaysia (UTM), 81310 Skudai, Johor, Malaysia 
advantage. In addition, the role of organization's service orientation in obtaining a sustainable competitive advantage in modern marketing literature has been recognized. Therefore, investigate of this service orientation, the relationship and strategy between the organization and the customer, it has become very important for organization to understand fundamentally and fulfill needs of consumer in order to prosper in a highly competitive market environment (Liang et al., 2010).

Another source of sustaining competitive advantages is IT infrastructure (Ling, 2011). It has been recognized as one of the crucial success element for organizations in contemporary business sphere to respond to market opportunities (Bhatt and Emdad, 2010). Nevertheless, empirical evidence reveals that IT infrastructure cannot lead to competitive advantage directly (Bhatt and Grover, 2005) though infrastructure characteristics permit complementary resources to be better leveraged. The basic aim of an IT infrastructure is to uphold and improve IT services; therefore, they are the base upon which the business procedures that drive an firm's success are founded on (Da Silva and Abreu, 2010).

Based on the literature, there are theoretical gaps on the relationship between market orientation, service orientation, IT infrastructure and job satisfaction. Thus, the research intends to reduce these gaps to explore the relationship between market orientation, service orientation and IT infrastructure with job satisfaction and creating the best model combining these four domain areas to produce a guideline for bank sector to implement market orientation, service orientation and IT infrastructure to improve job satisfaction. The works of the theorists propagating these models are viewed as important in the study on the relationship between $\mathrm{MO}$, $\mathrm{SO}$, ITIC and JS.

The objective of this study is to investigate whether Market Orientation (MO), Service Orientation (SO) and Information Technology Infrastructure (ITI) affect the Job Satisfaction (JS) as well as to identify factors and barriers that influence the implementation of $\mathrm{MO}, \mathrm{SO}$ and ITI to improve JS in banking industry. This study is intended to provide guidelines for banking industry to implement effective market orientation and service orientation culture and also information technology infrastructure to improve job satisfaction.

\section{Literature review}

Job satisfaction: Among the different variables of organizational behavior, job satisfaction is the most important and vastly studied for decades (Robbins, 2001). Obviously job satisfaction is affected by many elements and ultimately portrays employee well-being due to their research $(\mathrm{Wu}, 2009)$. In other words, if one is satisfied with their job then attitude is likely a performance indicator (Bodouva, 2010).

Job satisfaction is also said to be the pleasurable emotional state resulting from the appraisal of one's job as achieving or facilitating the achievement of one's job values (Locke, 1969). Additionally, it can be a global response to general job conditions and experience of and emotional response to various job aspects like work, superiors, wages, colleagues, firm policies and measures (Brown and Peterson, 1993). Conventionally, job satisfaction theory mentions that employee satisfaction or dissatisfaction can be due to work-related factors (Bodouva, 2010). Hartline and Ferrell (1996) generally define job satisfaction as an affective condition as a consequence of employees assessing their job. Moreover, according to George and Jones (2008), job satisfaction is the collection of feelings and beliefs that people have about their current jobs. People's levels or degrees of job satisfaction can range from extreme satisfaction to extreme dissatisfaction.

Also, job satisfaction encompasses employee attitudes and behaviors towards their research due to how they perceive their job as well as the affinity between individuals and their organizations (O'Reilly et al., 1991). These viewpoints are generally what lead to employee cognitive perceptions and assessment of their work environment (Weiss and Cropanzano, 1996). Clearly, job satisfaction is not simple but a multifaceted construct. Therefore, this study aims to operationalize both intrinsic and extrinsic elements of job satisfaction within the banking industry.

Market orientation: Market orientation refers to marketing concept implementation (Kohli and Jaworski, 1990). The idea of marketing plays a major role in increasing organization structure effectiveness and profitability such that a market-oriented organization's activities need to be directly relative to and consistent with the marketing concept (Kohli and Jaworski, 1990). This is why the Marketing Science Institute has prioritized market orientation research where Deshpande and Webster (1989) first made the connection between market orientation and organizational culture.

Market orientation was then seen as a set of organizational actions with behavioral activities (Kohli and Jaworski, 1990) and an organizational culture capable of delivering behaviors needed for creating superior customer value (Narver and Slater, 1990). Furthermore, Hurley and Hult (1998) suggest that market orientation has two vital elements; namely, a set of 
behaviors and the culture aspect while market orientation is seen by others as an innovation (Liu, 1995; Rogers, 1995; Fritz, 1996). Also, Castro et al. (2005) recognize that market orientation plays an important role in achieving and maintaining competitive advantage. So far, there is not enough experimental research since only some developed countries have expanded on and tested market orientation models (Zebal, 2003; Gheysari et al., 2012b). Therefore, this study has been conducted to diminish this empirical gap. Bank industry employees were particularly useful in determining to what extent the marketing orientation and concept are implemented.

Service orientation: Recent studies have recognized the role of service orientation in each company in getting to sustaining competitive advantage. Service orientation is described as the relationship between a company and its customers, crucial to understand in order to fulfill customer needs and for businesses to thrive in the recent highly competitive market grounds (Lytle and Timmerman, 2006; Marinova et al., 2008). Some organizations perceive service orientation as an obstacle to get around to minimize any negative customer interaction outcomes. For this reason, major focus is aimed at how service orientation affects business performance (Lytle et al., 1998; Homburg et al., 2002; Di Mascio, 2010) while only minimal academic research has examined what role and impact service orientation has on employee and job satisfaction.

There are many references in the literature of service marketing to suggest how crucial service orientation development is. Homburg et al. (2002) indicate two ways of establishing the service orientation concept; at the individual or micro organizational level and at the organizational level. Service orientation has been studied as an individual personality variable by Hogan et al. (1984) and McBride et al. (1993) among others. Hogan et al. (1984) presented the most note-worthy individual aspect description by saying that service oriented individuals are predisposed to being helpful, thoughtful, considerate and cooperative. Thus, service orientation is the result of individual worker attitudes manifested through their behavior. On the other hand, assessing service orientation from an organizational perspective helps bring to light particular organizational practices which contribute to superior organizational service orientation and performance (Lytle et al., 1998; Homburg et al., 2002). This study utilizes the organizational aspect for market orientation and service orientation, therefore organizational level only is assessed. Again, service orientation is the fundamental set of comparatively enduring organizational practices leading to service excellence development and delivery as a strategic marketing reaction to market data (Lytle et al., 1998). Based on Lytle et al. (1998), this research develops on the four attribute of service orientation, namely service leaderships, service encounter, service system and human resource management.

The way frontline workers relate to customers directly affects how successful service orientation is with the result of customer satisfaction being the topic of vast research (Homburg and Stock, 2005). The reason that frontline employees are very important groups in each organization is that the customer can form an opinion based on a single interaction with an employee and thus affect a firm's success; even though, it may have numerous divisions, employees and ultimately billion-dollar revenues. Organizations therefore aim to motivate and increase job satisfaction among their employees to gain more customers.

Information technology infrastructure capability: Information technology has been rapidly evolving thus impacting virtually employees anywhere since almost everyone needs to use IT in their job (Raghavan et al., 2008). If employees are faced with and can effectively use new software, learn new programs or keep up with various IT requirements, they will likely make fewer errors, become more efficient and therefore have increased job satisfaction (Diala, 2010; Gheysari et al., 2012a). IT has been discovered by many organizations to be a key element in being completive and profi in today's market since through IT infrastructure, they can maximize information resource utilization. Of course IT infrastructure comprises several elements that need to be acknowledged for best use such as IT services, human IT infrastructure and IT infrastructure components (Broadbent et al., 1996).

The 1980 s saw increasing studies supporting the claim that IT can be beneficial to a company by increasing entry barriers, bargaining potential with suppliers and customers and providing innovative products and services (McFarlan, 1984). From the 1990s onward, great emphasis has been placed by researchers and firm managers on IT to yield benefits for the company. From an economic perspective, company performance evaluation through the influence IT has on it has utilized Williamson (1995)'s transaction cost theory. It has been agreed that customers who make asset-specific investments in unique supplier-based IT and processes are likely to switch costs. IT has advantages but with time, it has been noticed that maintaining these advantages is challenging due to competitors reproducing and appropriating various successful applications (Mata et al., 1995; Sambamurthy and Zmud, 1997). IT is not a sole contributor to a firm's competitive advantage 
but advantage is also achieved through the company's ability to employ the benefits reaped through IT. It is in the way a company leverages IT to its advantage (Bhatt and Grover, 2005). International banking systems rely on the latest technology; however in developing countries such as Iran, various social, political and economic factors can hinder the use of such technology to fully benefit firms.

\section{MATERIALS AND METHODS}

The study adopted a qualitative research approach to explore the insight of the market orientation, service orientation, IT infrastructure and job satisfaction in banking sector and derive a relationship. The study comprises of semi structured interview.

Respondents: The main criterion used for the selection of the members is the level of knowledge about marketing concepts (MO and SO), human resource management (JS) and also ITI implementation in the bank as well as position and experience. There are four departments selected for the case study from Mellat Bank of Iran which comprise of Training Department, Research and Planning Center, Market Development and IT Department with high position and highly experienced. The background of the consultants is shown in Table 1.

The interview process: The general research questions formed parameters for analyzing documented data while the interviews included semi-structured interview aspects as well as probing questions in accordance to a set of questions or issues. The scope is to assess questions regarding ideas on how the bank can work on improving employee satisfaction, market orientation, service orientation and IT infrastructure.

The right sampling is deemed crucial to derive a practical and acceptable $\mathrm{MO}, \mathrm{SO}$ and ITIC approach and model to be recommended and adopted by the banking industry. For this study, the researcher found that 20 respondents were enough to get a viable data set in light of the fact that qualitative data collection does not need a particular number of participants. Yang (2008) recommends that 9-20 participants are sufficient to gain plenty of insight. A total of 20 individuals who satisfied the selection criteria voluntarily participated in the study. All the interview sessions were held between March, 2012 and June, 2012. The interviews were all conducted at a time and place convenient to the respondents. The longest interview lasted for $2: 10 \mathrm{~h}$ while the shortest interview lasted for $45 \mathrm{~min}$. The average time for the interviews was $1 \mathrm{~h}$ and $5 \mathrm{~min}$.

Most interviews began with portraying researcher appreciation towards employee participation in the study with the intention that employees felt valuable to the study and thus answer as honestly and sincerely as possible to all questions based on true feelings and experiences.

Through literature review, one of the most commonly utilized techniques in service research interviews discovered is the Critical Incident Technique (CIT). CIT relies on a set of procedures to collect, analyze content and categorize observations of human behavior and a critical incident is one that normally makes considerable contribution to a movement or occurrence (Gremler, 2004). Critical incident data is collected in many ways for service research but the most common method is to ask respondents to tell a story about an experience previously had. After data is collected, story content is assessed and for this, two tasks are carried out, namely deciding on a general framework of reference to describe the incidents and inducing category and subcategory development. During these tasks, the researcher should keep in mind the main study aim, reality of classifying incidents and how previously developed classification schemes on the topic are correlated (Gremler, 2004). Generally, the main reason to analyze content is to obtain a categorization scheme which gives insight on frequency and patterns of aspects affecting the studied topic.

\section{RESULTS AND DISCUSSION}

\section{Data analysis}

Barriers or challenges in implementation of market orientation: For better understand of the barriers in the implementation of market orientation in Mellat Bank of

\begin{tabular}{|c|c|c|c|c|}
\hline Code of respondents & Gender & Job title & Years of experience & Education level \\
\hline 1 & Male & Training Department & 12 & $\mathrm{PhD}$ (Education) \\
\hline 2 & Male & Market Development & 6 & Master (MBA) \\
\hline 3 & Female & Research and Planning & 6 & Master (Marketing) \\
\hline 4 & Male & IT Department & 5 & $\mathrm{PhD}$ (International marketing) \\
\hline 5 & Male & Market Development & 9 & $\mathrm{PhD}$ (Marketing) \\
\hline 6 & Male & Research and Planning & 8 & $\mathrm{PhD}$ (Marketing) \\
\hline 7 & Female & IT Department & 4 & $\mathrm{PhD}(\mathrm{IT})$ \\
\hline 8 & Female & Training Department & 15 & $\mathrm{PhD}$ (Human resources) \\
\hline 9 & Male & IT Department & 7 & Master (Marketing) \\
\hline 10 & Male & Research and Planning & 5 & $\mathrm{PhD}$ (Strategic) \\
\hline 11 & Male & Training Department & 38 & Master (Finance) \\
\hline 12 & Female & Market Development & 11 & $\mathrm{PhD}$ (International marketing) \\
\hline
\end{tabular}


Iran, the question: Do you find any barriers or challenges in the implementation of market orientation in Mellat Bank? was posted to the participants. The findings show that main barriers to the implementation of market orientation in Mellat Bank are lack of systematic and centralize research for tracking activities of customers and competitors ( 9 counts); parallel tasks, works and processes due to lacking of proper system ( 6 counts); lacking of market orientation culture ( 5 counts); infra organizational legislating limitations (4 counts); lack of coordination and unity between units ( 3 counts); lack of connection between pay and performance measures with MO concepts ( 3 counts); bureaucratic with insufficient flexibility of bank structure ( 2 counts); deep gap between old and new employees ( 2 counts); insufficient educated staff ( 2 counts) and relevant and accepted software is not available (1 count).

\section{Suggestions to improve market orientation initiatives:}

The findings show the suggestion to implement market orientation initiatives. Among the suggestions are strengthening and institutionalizing scientific marketing research through bank (5 counts); strengthen team working culture for better sharing information and increasing synergetic (4 counts); defining Product Lifestyle Management (PLM) for reducing service time and budget ( 3 counts); setting long term strategies (3 counts); establish a joint committee for better coordination, unity and integration between units and employees ( 3 counts); utilizing IT more to improve staff's tendency to implement MO (2 counts); staffs should be trained on the different aspect of MO (2 counts); develop private banking and giving solutions and consults to each customers ( 2 counts); removal and changing the old culture with work force down size, premature retirement, replacing forces and also force and training ( 2 counts); circulated information among all staffs and no limitation to specific individuals ( 2 counts) and using history of bank for attract customers (1 count).

Barriers or challenges in implementation of service orientation: Based on the interview findings, barriers that were identified are structural and telecommunication failures of whole country ( 5 counts); improper service atmosphere and unsuitable behavior with customers and staffs (4 counts); bureaucratic and traditional approach will stale new services and be predicted by competitors (4 counts); insufficient awareness on service orientation (4 counts); lack of systematic and centralize system (3 counts); conservative reactions and infra organizational limitations by Central Bank and government ( 2 counts); lack of organizational justice in compensation, rewards, promotion and encouragements connection to the staff's performance of service orientation ( 2 counts); lacking of service orientation culture and hardish changing it (2 counts); lake of proper training system for staffs (2 counts); fall into forgetfulness or procrastination of good services due to wide variety of services and persist on similar and not essential services (2 counts); insufficient human resource management in practical way (1 counts) and lacking of team working culture ( 1 count).

Suggestions to improve service orientation initiatives: There are several suggestions to improve service orientation that have been identified by the practitioners. Most of the practitioners suggested that holding and revised training courses constantly to have service orientation's staffs (5 counts); establish a good and stable service orientation policy (4 counts); establish real suggestion system for staffs and customers (4 counts); strengthening the sense of corporate citizen and sprit group working ( 4 counts); providing services for all customers not only especial groups ( 3 counts); defining product lifestyle in detail for knowing what behavior are in need at every step (3 counts); changing job, suspension, redemption or sack of inefficient employees (3 counts); flexibility environment instead of bureaucratic policies with authorization and independency ( 3 counts); recruitment of service oriented employees ( 2 counts) and clarifying decision making process ( 2 counts).

\section{Barriers or challenges in implementation of IT} infrastructure capability: Similar to other industry, in the banking industry, there are barriers in the implementation of IT infrastructure capability. Based on the interview findings, barriers that were identified are limitation of accessing the soft and hardware from outside of the bank (9 counts); low speed and disconnections of telecommunication and internet (5 counts); outsourcing can bring great risk, dependency and losing data ( 4 counts); insufficient awareness and confidence on ITI (3 counts); lacking of operating freely and political interference by government ( 2 counts); no systematic sharing information among all staffs ( 2 counts); relevant and accepted software is not available (2 counts); traditional thoughts and view of old manager ( 1 count); lack of flexible and comprehensive IT infrastructure planning ( 1 count) and defects in categorizing of financial and statistical fields (1 count).

Suggestions to improve IT infrastructure capability initiatives: There are several suggestions to improve ITIC 
capabilities that have been identified by the practitioners. Most of the practitioners suggested that to cover all IT subsidiary companies for removing risk, dependency and losing data ( 9 counts); establishing system approach throughout departments ( 4 counts); user friendly and be not complexity of processes to increasing the confidence of customers (4 counts); government and Central Bank should establish IT policy and making culture ( 3 counts); all staffs should have access to ITI fairly and systematically ( 2 counts); all staffs should be sent for IT training ( 2 counts); imitate the pattern from the world's successful banks (2 counts); creation of electronic database of customer's records (1 count); creation of mechanisms in sharing ideas between IT sector and other sectors (1 count) and considering all customers by the services ( 1 count).

Barriers or challenges in achievement of job satisfaction: Based on the findings, it is apparent that most of the practitioners believed that the main barriers to achieve job satisfaction among employees are discriminations and injustice in payments at different levels ( 7 counts); injustice and not systematic job promotion ( 6 counts); society's welfare and economy are not proper (Imbalance between salaries and expenses) ( 5 counts); not proper relationship between managers and staffs due to bureaucratic environment (5 counts); weakness in good and quick information sharing (3 counts); lack of mechanisms of assessing staff functions (3 counts); lacking of proper culture and personality ( 2 counts); lacking of team working culture ( 2 counts) and mismatch of jobs and staffs ( 2 counts).

Suggestions to improve job satisfaction: There are possibly many suggestions to improve the employee job satisfaction in banking industry that have been identified by the practitioners. Most of the practitioners suggested that improve systematic performance evaluation and payments ( 7 counts); changing job, suspension, redemption or sack of Inefficient and unsatisfied employees (5 counts); meritocracy and justice in job promotions that helps fair behaviors to the employees (4 counts); revising training structure (4 counts); all elements and who are involved with an employee should be seen ( 3 counts); correcting incentive and encouragement system based on performance ( 3 counts); giving freedom, authority and responsibility to employees (3 counts); redesigning space and equipment of the branches constantly (2 counts); improve the accomplishment and achievement's filling ( 2 counts); stress management ( 2 counts) and measuring branches and staff productivity (1 count).
Whether MO and SO influence job satisfaction: Based on the findings, it is apparent that most of the practitioners believed that there is a mutual relationship between market orientation and service orientation with job satisfaction (6 counts) while some of respondents believe that without adding some variables (Control, moderator or mediator variables), there is no relationship between market orientation and service orientation with job satisfaction (5 counts). Also, some participants perceived market orientation and service orientation could improve the employee job satisfaction (8 counts), although there is converse relationship between market orientation and service orientation with job satisfaction (1 count).

The impact of ITIC on market orientation, service orientation and job satisfaction: Based on the results, it is apparent that most of the practitioners believed that IT infrastructure could improve the relationship between market orientation and service orientation with employee job satisfaction through improve effective communication between bank and customers ( 8 counts); provide more security, simplicity and faster services (6 counts); developing win-win relationship for customers, employees and the bank ( 5 counts); improving employee productivity (5 counts); increases customer and job satisfaction (5 counts); reduce the work volume, transactions and expenses (4 counts); provides a competition advantageous and improve the bank potency in coming up the rival's threats (3 counts); reduce fault, mistakes and errors (3 counts); develop private and internet banking for giving solutions and consult electronically ( 2 counts); improve staffs tendency to implement market orientation and service orientation (2 counts); strengthening electronic marketing research (2 counts) and better and faster understanding of market and customer's needs (1 count).

MO-SO-ITI-JS framework: According to the data analysis, the revised market orientation, service orientation, job satisfaction and IT infrastructure (MO-SO-JS-ITI), framework is extracted which is present in Fig. 1 as a main contribution of this study. The revised MO-SO-JS-ITI framework takes into account all the major findings from the qualitative analysis. However, several push factors including internal and external factors have been identified in the model that influences the implementation of $\mathrm{MO}, \mathrm{SO}$ and ITI based on job satisfaction. Furthermore, barriers to the implementation of $\mathrm{MO}, \mathrm{SO}$ and ITIC also identified to ensure that $\mathrm{MO}, \mathrm{SO}$ and ITIC can successfully improve the employee job 


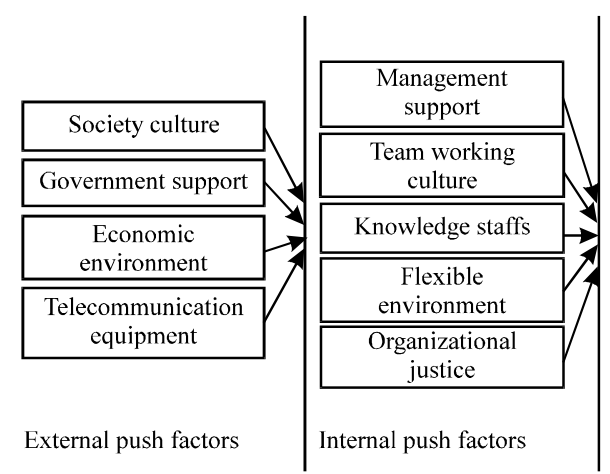

Fig. 1: MO-SO-ITI-JS framework

satisfaction. The model in Fig. 1 incorporates the qualitative findings as contextual factors that affect the degree of relationship between $\mathrm{MO}$, SO and ITIC throughout the job satisfaction. The model proposed that the internal factors, external factors and barriers are elements that should be focused by the bank managers to facilitate the $\mathrm{MO}, \mathrm{SO}$ and ITIC implementation to improve job satisfaction.

The framework in Fig. 1 shows that market orientation, service orientation and IT infrastructure can influence job satisfaction in banking industry. By implementing market orientation including customer orientation, competitor orientation and niter-functional coordination, the job satisfaction can be improved. This finding is supported by Ruekert (1992), Menguc (1996), Hampton and Hampton (2004), Kirca et al. (2005), Zhou et al. (2008), Grinstein (2008) and Rodrigues and Pinho (2010) who found that a positive relationship between market orientation and job satisfaction improvement. The framework in Fig. 1 proposed that service orientation culture can influence job satisfaction. Service orientation can be categorized into service leadership, service encounter, service system and human resource management. The results of this study is agreed with previous research who found that service orientation has impact on employee job satisfaction (Lytle et al., 1998; Yoo et al., 2000; Dean, 2004; Gonzalez and Garazo, 2006; Chen, 2007; Yoon et al., 2007).

The framework in Fig. 1 also shows that ITIC facilities can influence job satisfaction. ITIC can be categorized into integration capability, data management capability, collaboration capability, security capability and utility capability. For integration capability, communication tools such as email can facilitate the communication between employees and customers. With regards to data management capability, banks should improve data management through establishing databases includes database management systems (Kim, 2001), data storing
(Databases or online repository), data tracking, data transaction, data analyzing and data translating (Zack, 2002). Popular data management such as data warehousing, data mining and knowledge mining are actually possible without captured data. As for collaboration capability, intranet system, instant messaging, SMS, e-mail, discussion groups, blogs, wikis, bulletin boards, project workspaces, task lists, calendars, document sharing and corporate portals should be established to share technical documents and other electronic resources (Kim, 2001; Benbya et al., 2004; Harris-Jones, 2006). For security capability, banks should practice backup, computer password, anti-spy ware and uninterrupted power supply to secure their information. As for IT utilities, banks should provide IT training, IT planning and IT education and also technical support to smoothen the IT related operations.

Finally, through the qualitative research, it can be concluded that the importance of implementation of market orientation, service orientation and IT infrastructure to improve job satisfaction has been emphasized as an important part of any effective management strategy. With regards to the results, the internal factors, external factors and barriers are elements that should be focused by the bank managers to facilitate execution market and service orientation culture and also IT infrastructure for improving employee satisfaction.

Several push factors have been identified including internal and external. Internally, management support, team working culture, knowledge staffs, flexible environment and organizational justice are deemed necessary to expedite the implementation of market orientation and service orientation to improve job satisfaction. Externally, it is noted that society culture, government support, economic environment and telecommunication equipment can be push factors to the success execute of market orientation and service orientation and improve job satisfaction. 
Furthermore, a clear signal to the banking industry is to be aware of the barriers (Governmental, organizational and managerial) and listed the strategy to overcome the barriers to ensure the success of market orientation and service orientation and improve job satisfaction. Among the critical barriers which are required to be managed are improper telecommunication equipment, Infra organizational restrictions, bureaucratic with insufficient flexibility of structure, economic and welfare conditions, outsourcing risk, lack of organizational justice, lack of team working culture, lack of systematic and centralize system, improper training system, deep gap between old and new staffs, mismatch of jobs and staffs, insufficient knowledge staffs and boundary barriers.

\section{CONCLUSION}

This study has attempted to address the issues of Market Orientation (MO), Service Orientation (SO) and IT Infrastructure Capability (ITIC) contribution to Job Satisfaction (JS) in banking industry as well as other factors and barriers that affect the implementation of $\mathrm{MO}, \mathrm{SO}$ and ITI to improve JS. The result of qualitative analysis shows that there is a significant influence of $\mathrm{MO}, \mathrm{SO}$ and ITIC to IS. The link between all variables was conceptualized in a way that $\mathrm{MO}, \mathrm{SO}$, ITIC and other factors and barrier management contribute to job satisfaction. Based on the qualitative analysis, MO-SO-ITI-JS framework has been derived to show the effect of $\mathrm{MO}$, SO, ITI other factors and barriers to job satisfaction.

In addition, a clear signal to the banking industry is to be aware of the barriers and listed the strategy and suggestions to overcome the barriers to ensure the success of market orientation, service orientation and IT infrastructure to improve job satisfaction. Among, the critical barriers of market orientation which are required to be managed are lack of systematic and centralize research and parallel tasks, works and processes. Also, important barriers that were identified to the implementation of service orientation are structural and telecommunication failures of whole country and improper service atmosphere and bureaucratic and traditional approach. In addition, main barriers that were identified in the implementation of IT infrastructure capability are limitation of accessing the soft and hardware from outside of the bank and low speed and disconnections of telecommunication and internet and outsourcing. Also, most of the practitioners believed that the main barriers to achieve job satisfaction among employees are discriminations and injustice in payments, injustice and not systematic job promotion and society's welfare and economy are not proper.
To summarize, the earlier findings provide a guiding principle for market orientation, service orientation and IT infrastructure to improve job satisfaction through the understanding of $\mathrm{MO}, \mathrm{SO}$ and ITI contribution to job satisfaction. Furthermore, the findings also address the internal and external factors as well as barriers to ensure the success of the implementation. Thus, the management of banks should take advantage of the current positive perception and movement towards the implementation of market orientation, service orientation and IT infrastructure to improve job satisfaction.

There are many areas that warrant further studies. For the present study, the sample was chosen from bank industry. Further comparative works may be conducted across different industries and cultures such as tourism, hotels, hospital, etc. Comparisons among different industries can help to understand the pattern of market orientation, service orientation and ITI strategies implemented across different industries so that more focused research attention on MO-SO-ITI and JS can be made. A possible study can be carried out on the private and public sectors. On the other hand, it has been assumed that an organization's knowledge grows over time. An organization may not be aware of it, may not be making best use of it or may not be managing well in order to enhance those activities that lead to efficient and effective knowledge growth. Therefore, the focus is not on how and why an organization knows or ways of knowing but rather on developing a framework that allows one to understand and apply market orientation and service orientation to achieve job satisfaction with regard to role of IT infrastructure. Also, attaining all data from specialist and managers may result in inflated correlations and therefore, multiple measures of the constructs taken from different sources such as frontline employees would be appropriate.

\section{RECOMMENDATIONS}

There are several suggestions to improve market orientation, service orientation, job satisfaction and IT infrastructure that have been identified by the practitioners. Among, the suggestions to implement market orientation are strengthening and institutionalizing scientific marketing research and strengthen team working culture. Also, most of the practitioners suggested that for improving service orientation, holding and revised training courses constantly, establish a good and stable service orientation policy and establish real suggestion system for staffs and customers are need. On the other hand, most of the practitioners suggested that for improving IT infrastructure should cover all IT subsidiary 
companies for removing risk, dependency and losing data, establishing system approach throughout departments and user friendly and be not complexity of processes. Also, most of the practitioners suggested that improve systematic performance evaluation and payments; changing job, suspension, redemption or sack of inefficient and unsatisfied employees and meritocracy and justice in job promotions is necessary for improving job satisfaction among employees.

\section{REFERENCES}

Benbya, H., G. Passiante and N.A. Belbaly, 2004. Corporate portal: A tool for knowledge management synchronization. Int. J. Inform. Manage., 24: 201-220.

Bhatt, G. and V. Grover, 2005. Types of IT capabilities and their role in competitive advantage: An empirical study. J. Manage. Inf. Sys., 22: 253-277.

Bhatt, G.D. and A.F. Emdad, 2010. An empirical examination of the relationship between IT infrastructure, customer focus and business advantages. J. Syst. Inform. Technol., 12: 4-16.

Bodouva, J.J., 2010. The influence of employee perceptions of the work climate on perceived service quality and their relationships with employee goal orientations, employee self-efficacy and employee job satisfaction. Ph.D. Thesis, Nova Southeastern University, Florida.

Broadbent, M., P. Weill, T. O'Brien and B.S. Neo, 1996. Firm context and patterns of IT infrastructure capability. Proceedings of the Seventeenth International Conference on Information Systems, December 16-18, 1996, Cleveland, Ohio, USA., pp: 174-194.

Brown, S.P. and R.A. Peterson, 1993. Antecedents and consequences of salesperson job satisfaction: Meta-analysis and assessment of causal effects. J. Market. Res., 30: 63-77.

Castro, C.B., E.M. Armario and M.E.S. del Rio, 2005. Consequences of market orientation for customers and employees. Eur. J. Market., 39: 646-675.

Chen, Y.J., 2007. Relationships among service orientation, job satisfaction, and organizational commitment in the international tourist hotel industry. J. Am. Acad. Bus., 11: 71-82.

Crosby, L.A. and N. Stephens, 1987. Effects of relationship marketing on satisfaction, retention and prices in the life insurance industry. J. Market. Res., 24: 404-411.
Da Silva, L.F. and F. Abreu, 2010. An IT infrastructure patterns approach to improve IT service management quality. Proceedings of the 7 th International Conference on the Quality of Information and Communications Technology, September 29-October 2, 2010, Porto, pp: 171-176.

Dean, A.M., 2004. Links between organisational and customer variables in service delivery: Evidence, contradictions and challenges. Int. J. Serv. Indus. Manage., 15: 332-350.

Deshpande, R. and F.E. Webster Jr., 1989. Organizational culture and marketing: Defining the research agenda. J. Market., 53: 3-15.

Di Mascio, R., 2010. The service models of frontline employees. J. Market., 74: 63-80.

Diala, I.S., 2010. Job satisfaction among information technology professionals in the Washington DC area: An analysis based on the Minnesota Satisfaction Questionnaire. Ph.D. Thesis, Capella University, Minneapolis.

Fritz, W., 1996. Market orientation and corporate success: findings from Germany. Eur. J. Market., 30: 59-74.

George, J.M. and G.R. Jones, 2008. Understanding and Managing Organizational Behavior. 5th Edn., Pearson Prentice Hall, USA., ISBN: 13-9780132057035, Pages: 707.

Gheysari, H., A. Rasli, P. Roghanian and H. Jebur, 2012a. The role of Information Technology Infrastructure Capability (ITIC) in management. Int. J. Fundam. Psychol. Social Sci., 2: 36-40.

Gheysari, H., A. Rasli, P. Roghanian and N. Norhalim, $2012 \mathrm{~b}$. A review on the market orientation evolution. Procedia-Social Behav. Sci., 40: 542-549.

Gonzalez, J.V. and T.G. Garazo, 2006. Structural relationships between organizational service orientation, contact employee job satisfaction and organization behavior. Int. J. Serv. Ind. Manage., 17: $23-50$.

Gremler, D.D., 2004. The critical incident technique in service research. J. Serv. Res., 7: 65-89.

Grinstein, A., 2008. The relationships between market orientation and alternative strategic orientations: A meta-analysis. Eur. J. Market., 42: 115-134.

Hampton, G.M. and D.L. Hampton, 2004. Relationship of professionalism, rewards, market orientation and job satisfaction among medical professionals: The case of Certified Nurse-Midwives. J. Bus. Res., 57: 1042-1053.

Harris-Jones, C., 2006. Knowledge management past and future. http://www.kmworld.com/Articles/Editorial/ Features/Knowledge-management-past-and-future14832.aspx. 
Hartline, M.D. and O.C. Ferrell, 1996. The management of customer-contact service employees: An empirical investigation. J. Market., 60: 52-70.

Hogan, J., R. Hogan and C.M. Busch, 1984. How to measure service orientation. J. Applied Psychol., 69: $167-173$.

Homburg, C. and R.M. Stock, 2005. Exploring the conditions under which salesperson work satisfaction can lead to customer satisfaction. Psychol. Market., 22: 393-420.

Homburg, C., W.D. Hoyer and M. Fassnacht, 2002. Service orientation of a retailer's business strategy: dimensions, antecedents and performance outcomes. J. Mark., 66: 86-101.

Hurley, R.F. and G.T.M. Hult, 1998. Innovation, market orientation and organizational learning: An integration and empirical examination. J. Market., 62: $42-54$.

Kim, S.K., 2001. An empirical study of the relationship between knowledge management and information technology infrastructure capability in the management consulting industry. University of Nebraska- Lincoln Paper AAI3034381, http:// digitalcommons.unl.edu/dissertations/AAI3034381/.

Kirca, A.H., S. Jayachandran and W.O. Bearden, 2005. Market orientation: A meta-analytic review and assessment of its antecedents and impact on performance. J. Market., 69: 24-41.

Kohli, A. and B.J. Jaworski, 1990. Market orientation: The construct, research proposition and managerial implications. J. Market., 54: 1-18.

Liang, R.D., H.C. Tseng and Y.C. Lee, 2010. Impact of service orientation on frontline employee service performance and consumer response. Int. J. Market. Stud., 2: 67-75.

Ling, L.S., 2011. Achieving Competitive Advantage (CA) through Information Infrastructure Capability (IIC): An empirical justification. Communications IBIMA, Vol. 2011. 10.5171/2011.842405.

Liu, H., 1995. Market orientation and firm size: An empirical examination in UK firms. Eur. J. Market., 29: $57-71$.

Locke, E.A., 1969. What is job satisfaction? Performance Organiz. Behav. Hum. Perform., 4: 309-336.

Lytle, R.S. and J.E. Timmerman, 2006. Service orientation and performance: An organizational perspective. J. Serv. Market., 20: 136-147.

Lytle, R.S., P.W. Hom and M.P. Mokwa, 1998. SERV* OR: A managerial measure of organizational service-orientation. J. Retail., 74: 455-489.

Marinova, D., J. Ye and J. Singh, 2008. Do frontline mechanisms matter? Impact of quality and productivity orientations on unit revenue, efficiency and customer satisfaction. J. Market., 72: 28-45.
Mata, J., P. Portugal and P. Guimaraes, 1995. The survival of new plants: Start-up conditions and post-entry evolution. Inter. J. Ind. Organiz., 13: 459-481.

McBride, S.L., M.J. Brotherson, H. Joanning, D. Whiddon and A. Demmitt, 1993. Implementation of family-centered services. J. Early Intervention, 17: $414-430$

McFarlan, F.W., 1984. Information technology changes the way you compete. Harvard Bus. Rev., 62: 98-103.

Menguc, B., 1996. The influence of the market orientation of the firm on sales force behavior and attitudes: Further empirical results. Int. J. Res. Market., 13: $277-291$

Narver, J.C. and S.F. Slater, 1990. The effect of a market orientation on business profitability. J. Market., 54: $20-35$.

O'Reilly, C.A., J. Chatman and D.F. Caldwell, 1991. People and organizational culture: A profile comparison approach to assessing person-organization fit. Acad. Manage. J., 34: 487-516.

Raghavan, V.V., T. Sakaguchi and R.C. Mahaney, 2008. An empirical investigation of stress factors in information technology professionals. Inform. Res. Manage. J., 21 : 38-62

Robbins, S.P., 2001. Organizational Behavior. Prentice-Hall, Upper Saddle River?, NJ.

Rodrigues, A.P. and J.C.M.R. Pinho, 2010. Market orientation, job satisfaction, commitment and organisational performance: The specific case of local public sector. Trans. Government: People Process Policy, 4: 172-192

Rogers, J.D., K.E. Clow and T.J. Kash, 1994. Increasing job satisfaction of service personnel. J. Serv. Market., 8: 14-26.

Rogers, E., 1995. Diffusion of Innovations. The Free Press, New York.

Ruekert, R.W., 1992. Developing a market orientation: An organizational strategy perspectives. Int. J. Res. Market., 9: 225-245.

Sambamurthy, V. and R. Zmud, 1997. At the Heart of Success: Organizationwide Management Competencies. In: Steps to the Future: Fresh Thinking on the Management of IT-Based Organizational Transformation, Sauer, C. and P.W. Yetton, (Eds.). Jossey-Bass, San Francisco, California, ISBN-13: 9780787903589, pp: 143-163.

Weiss, H.M. and R. Cropanzano, 1996. Affective Events Theory: A Theoretical Discussion of Affective Experiences at Work. In: Research in Organizational Behavior, Staw, B.M. and L.L. Cummings (Eds.). Vol. 18, JAI Press, Greenwich CT., USA., pp: 1-74. 
Williamson, O.E., 1995. Transaction Cost Economics and Organization Theory. In: Organization Theory: From Chester Barnard to the Present and Beyond, Williamson, O.E. (Ed.). Oxford University Press, New York, USA., pp: 207-256.

Wu, F., 2009. The relationship between leadership styles and foreign english teachers job satisfaction in adult english cram schools: Evidences in Taiwan. J. Am. Acad. Bus. Cambridge, 14: 75-82.

Yang, L.M., 2008. An examination of education service quality at collegiate physical education departments in Taiwan: Using a gap analysis approach. $\mathrm{Ph}$. D. Thesis, United States Sports Academy, USA.

Yoo, J.N., Y.J. Lee and Y.K. Lee, 2000. The impact of service orientation on employee satisfaction by hotel grade. J. Tourism Sci., 23: 138-155.
Yoon, S.J., D.C. Choi and J.W. Park, 2007. Service orientation: Its impact on business performance in the medical service industry. Serv. Ind. J., 27: 371-388.

Zack, M.H., 2002. Developing a Knowledge Strategy. In: The Strategic Management of Intellectual Capital and Organizational Knowledge, Choo, C.W. and N. Bontis, (Eds.). Oxford University Press, New York, pp: $255-276$.

Zebal, M.A., 2003. A synthesis model of market orientation for a developing country-the case of Bangladesh. Ph.D. Thesis, Victoria University.

Zhou, K.Z., J.J. Li, N. Zhou and C. Su, 2008. Market orientation, job satisfaction, product quality and firm performance: Evidence from China. Strategic Manage. J., 29: 985-1000. 